\title{
The Effect of Lateral Wedge Insole on Mediolateral Static Balance in Patients with Mild to Moderate Knee Osteoarthritis
}

\author{
Mahsa Zangi ${ }^{1}$, Maryam Jalalii ${ }^{*}$, Elham Esfandiari ${ }^{1}$, Hamid Reza Yazdi² \\ 1. Orthotics and Prosthetics Department, Faculty of Rehabilitation Sciences, Iran University of Medical Sciences, \\ Tehran, Iran \\ 2. Firoozgar Hospital, Faculty of Medicine, Iran University of Medical Sciences, Tehran, Iran
}

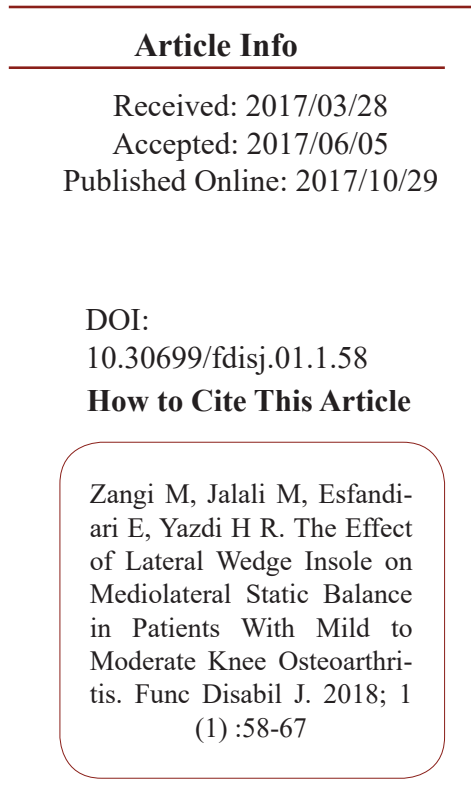

Use your device to scan and read the article online

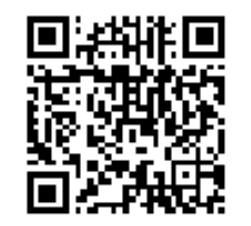

\begin{abstract}
Background and Objectives: Balance has reported to be impaired in patients with knee osteoarthritis. Lateral wedged insoles, have shown positive effect on parameters like knee adduction moment and pain. As a result, the factors that have been shown to reduce the parameters associated with knee osteoarthritis are anticipated to be effective in improving balance. The aim of this study was to investigate the immediate and four-week effects of lateral wedged insoles on static balance in patients with mild and moderate osteoarthritis of knee medial compartment.
\end{abstract}

Methods: 18 patients (mean age $=53 \pm 6.07)$ and body mass index $(26 / 1 \pm 2.1 \mathrm{~kg} / \mathrm{m} 2)$ with painful mild and moderate knee osteoarthritis according to the Kellgren-Lawrence grading were recruited. Static standing balance was assessed while standing for 60 seconds on a force plate in three different footwear and two vision conditions: barefoot, wearing shoes without lateral wedged insoles and wearing shoes with lateral wedged insole in open and closed eye conditions. Pain intensity and static standing balance in the mediolateral direction (through the displacement and velocity of center of pressure) were investigated immediately and 4 weeks later.

Results: Lateral wedged insoles had no immediate effect on the center of pressure mediolateral displacement $(P=0.70)$ and velocity $(P=0.08)$. Using the lateral wedged insoles for 4 weeks resulted in significant improvement of pain $(P<0.001)$ in mediolateral center of pressure displacement $(P<0.001)$ and velocity $(P<0.001)$.

Conclusion: No significant immediate effect was seen on the average displacement and velocity of the center of pressure in the mediolateral direction while wearing lateral wedged insoles. Measured parameters improved after 4 weeks. Effect of lateral wedged insoles as a non-invasive treatment can be considered for improving the postural balance in those with knee osteoarthritis.

Keywords: Foot Orthoses, Knee Osteoarthritis, Lateral Wedge, Static Balance

Corresponding Information:

Maryam Jalali, PhD, Orthotics and Prosthetics Department, Faculty of Rehabilitation Sciences, Iran Univer-

sity of Medical Sciences, Tehran, Iran. Email: jalali.m@iums.ac.ir

Copyright (C) 2018, Function and Disability Journal. This is an open-access article distributed under the terms of the Creative Commons Attribution-noncommercial 4.0 International License which permits copy and redistribute the material just in noncommercial usages, provided the original work is properly cited.

\section{Introduction}

Knee osteoarthritis is one of the most common orthopedic disorders. Over $13 \%$ of individuals at the ge of 55 to 64 and $17 \%$ between 65 and 74 endure pain due to osteoarthritis, and are limited in their activities and have difficulty walking (Davis, Ettinger, Neuhaus, \& Mallon, 1991; Pritzker et al., 2006). Prevalence of knee osteoarthritis increases with age (Mousavi, 2001). In Iran, the prevalence of osteoar- thritis has been estimated to be 19.3\% (Davatchi et al., 2009). Knee involvement in the medial compartment is about 10 times of that of the lateral compartment, and one reason for this could be the impact of 60 to 80 percent of bodyweight on the medial knee compartment in mid-stance while walking (Gök, Ergin, \& Yavuzer, 2002). A decrease in the cartilage thickness of the medial compartment and changes in the alignment towards the varus result in an increase in knee adduc- 
tion moment, which increases the risk and progression of the osteoarthritis and also damage to the articular cartilage (Katsuragawa, Fukui, \& Nakamura, 1999), and hence imbalance of the knee muscles (Sohrabi, Khademi-Kalantari, AkbarZadeh-Baghban, Rezaee, \& Hosseini, 2014). Among the disorders reported in individuals diagnosed with knee osteoarthritis is balance impairment (Ganesan, Lee, \& Aruin, 2014). Various factors such as impairment of proprioception resulting from defects in joint cartilage and surrounding structures are proposed as the balance impairing mechanism in these individuals (Kahlaee, Sadeghi, Jamebozorgi, \& Yousefian Molla, 2015). Maintaining balance is an important indicator of physical function and prevents falls (Sadeghi \& Alirezaei, 2008). Falls can have serious consequences such as fractures, loss of independence and other skeletal injuries (Hassan, Doherty, Mockett, \& Doherty, 2002). In the previous literature, mediolateral balance impairment, both in standing and in balance challenging activities increase the risk of fall extra space before parentheses (Brauer, Burns, \& Galley, 2000).

In management of knee osteoarthritis, non-surgical treatments such as physiotherapy, pharmacologic therapy or use of orthoses like shoe modifications or insoles are considered the initial therapeutic approaches (Mousavi, 2001). The aims of these therapies are to reduce pain, enhance physical function and also minimize other complications of the disease such as balance impairment and fall (Alshawabka, Liu, Tyson, \& Jones, 2014). Among the common orthoses used in this condition are lateral wedged insoles. Lateral wedge insoles increase the foot pronation and results in lateral displacement of the center of pressure. As a result, knee adduction moment, load onto the medial compartment and pain decrease and changes in foot mechanics indirectly affect the knee (Ahmadi, Forghany, Nester, \& Jones, 2014). Despite prescribing lateral wedged insoles as a means of managing osteoarthritis of the knee joint (Maly, Culham, \& Costigan, 2002), studies that have been carried out on balance have more often used clinical tests or reported the immediate effects of lateral wedged insoles on velocity and displacement of the center of pressure
(Hsieh, Lee, Lo, \& Liao, 2013).

Therefore, in order to obtain a better outlook on the effect of lateral wedged insoles on osteoarthritis, the immediate and 4-week effects of using lateral wedged insoles on the static balance in patients with mild and moderate knee medial compartment osteoarthritis has been studied.

\section{Material and Methods}

The current study is an interventional and quasi-experimental type. The committee of ethics of Iran University of Medical Sciences has approved the research and its phases. The participants were among patients visited at Firoozgar hospital, took part in the study after completing the consent form. The sampling method was non-probability sampling technique. The criteria to participate in the study included grades II and III osteoarthritis of medial knee compartment based on the Kellgren \& Lawrence (K\&L) classification in at least one knee (Ahmadi et al., 2014), with the age 40 years and above, and knee pain while walking scored 3 or more based on the Visual Analogue Scale. Participants were introduced to the researcher by the orthopedic specialist. The criteria considered for exclusion included individuals with isolated patellofemoral joint osteoarthritis, lateral compartment osteoarthritis of tibiofemoral joint, type I or IV osteoarthritis, neuromuscular problems, previous surgical records of the knee or injection of corticosteroids during the past 5 months (Ahmadi et al., 2014), and using foot ortheses during the past 6 months or using assistive devices while walking.

\section{Instruments}

Static balance was measured using a Kistler force plate (Swiss, AMTI) with a frequency of $1000 \mathrm{~Hz}$ in the biomechanics laboratory of orthotics and prosthetics department (faculty of Rehabilitation Sciences, Iran University of Medical Sciences).

\section{Therapeutic Intervention}

In this study, medical insoles with $5^{\circ}$ lateral wedge (figure 1) made of high density ethyl vinyl acetate (EVA) were used (Hsieh et al., 2013). In the current study, the insoles gradually become thinner near the 
head of the metatarsals and reach a thickness of 4.5 $\mathrm{mm}$ in order to ensure a comfortable fit in the shoe (Russell \& Hamill, 2011). Insoles are built based on conventional patterns and the wedge is created along the entire insole length. The high density EVA is resistant enough against pressure, so that the wedge shape of insoles remains intact during the 4 weeks of use. However, the flexibility of material was also considered in order to provide enough comfort while wearing orthoses in the shoe and push-off phase of walking. Lateral wedged insoles were placed beneath the shoe lining of the involved limbs of individuals with knee osteoarthritis and an insole without wedge was placed for the opposite limbs (in unilateral cases). Insoles were placed in their own shoe. Prior to their attendance at the laboratory, the participants were reminded of shoe characteristics including shoe heel, toe box, adequate shoe size and depth, slip resistance, and etc. (Iglesias, de Bengoa Vallejo, \& Pena, 2012).

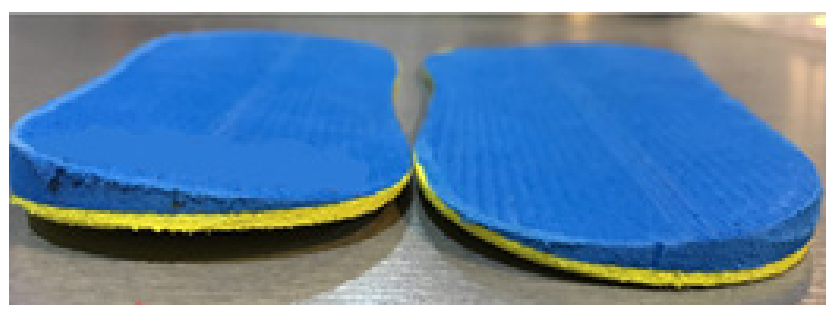

Fig 1. Full-length lateral wedged insoles

\section{Procedure}

To measure the pain of individuals, the visual analogue scale was used at the beginning and end of the study. With regard to the severity of pain they felt in the joint, participants were asked to mark the pain on a $10 \mathrm{~cm}$ line (Parkes et al., 2013). Also, to evaluate the qualitative effect during 4 weeks, they were asked to use the insole for at least 5 to 10 hours during their daily activities and make note of the applications and problems associated with using the insoles (Toda \& Segal, 2002). In fact, the study duration was 4 weeks, and the patients were supposed to use the insoles during these four weeks as assigned and return to the testing site (biomechanics laboratory of orthotics and prosthetics department at IUMS rehabilitation sciences faculty) after four weeks. All tests were done at the beginning of the study and four weeks afterwards.
The evaluation of static balance was done in three conditions; barefoot (without shoes), wearing shoes without lateral wedged insoles, and wearing shoes with lateral wedged insoles.

Prior to carrying out the tests, the procedure was completely depicted for the participants and they were notified of the significance of their cooperation. A 2-minute break was given to the participants between each test and they were asked to immediately inform if they felt tired during the test. Selecting the test conditions for each individual was completely random. Each test condition was repeated three times and reference data was calculated from the average of these three repetitions. Participants were asked to stand on both parallel feet steadily. Arms were placed along the body and breathing was normal (Ahmadi et al., 2014). Data collection and recording began from the point where the participant was in a stable condition on the force plate and this continued for $60 \mathrm{sec}-$ onds.

In order to evaluate the effect of visual information on balance control, the tests were done in both conditions of eyes open and closed. All measurements were repeated four weeks after using the lateral wedged insoles.

\section{Data Analysis}

The center of pressure parameters for evaluating balance stability in this study include velocity and displacement of the center of pressure in the mediolateral direction in three footwear conditions of barefoot, with shoes having lateral wedged insoles, shoes and two vision conditions; eyes open and closed.

A low pass filter with a cut off frequency of $10 \mathrm{~Hz}$ (Ganesan et al., 2014) applied to the data. The mid 20 seconds of recordings were used and static balance was measured by means of average displacement and velocity of the center of pressure in mediolateral direction using MATLAB software (version 2.0, R14, 7.0.4.365) (Satvati, Karimi, Tahmasebi Boldaji, \& Pool).

\section{Statistical Analysis}

All analyses were done through SPSS software. To obtain conformity of the data with normal distribu- 
61. The Effect of Lateral Wedge Insole ...

tion, the Kolmogorov-Smirnov test was used. With regard to the normal distribution of data, repeated measure analysis of variance was carried out for inferential analysis of data. Significance level was considered to be 0.05 .

\section{Results}

18 patients (3 males and 15 females) with mild and moderate knee osteoarthritis (medial compartment) with a mean age of $53 \pm 6.1$ years and BMI of $26 \pm 2.1 .1 \mathrm{~kg} / \mathrm{m} 2$ took part in the study. $61.1 \%$ of the patients had grade II osteoarthritis and $38.9 \%$ of the patients diagnosed with grade III. The average pain of these patients based on the visual analogue scale was $6.5 \pm 2.5$ at the beginning of the study, and 4 weeks later it reached $4.9 \pm 2.6(P=0.001)$.

The mean and standard deviation of results obtained from the displacement of center of pressure in medio- lateral direction are shown in table (1).

Results of the repeated measure analysis (table 2) showed a significant difference in the main effect of visual status (open and closed eyes) $(P=0.02, \mathrm{~F}=6.49)$, the main effect of time $(P<0.001, \mathrm{~F}=29.1)$ and the interaction effect of intervention, time and visual status $(P=0.03, \mathrm{~F}=3.9)$ on the average displacement of center of pressure in mediolateral direction.

The mean and standard deviation of the obtained results of the quantitative analysis of center of pressure velocity in mediolateral direction are shown in table 3.

Repeated measure analysis results (table 4) show a significant difference in the main effect of visual status on velocity in the mediolateral direction $(P=0.0004, \mathrm{~F}=11.3)$ and the main effect of time $(P<0.001, \mathrm{~F}=34.8)$.

Table 1. Mean and standard deviation for center of pressure displacement in mediolateral direction

\begin{tabular}{|c|c|c|c|c|}
\hline Orthotic intervention & Visual Status & Time & Mean (mm) & Standard deviation ( $\mathrm{mm}$ ) \\
\hline \multirow{4}{*}{ Barefoot } & \multirow{2}{*}{ Eyes open } & Beginning of study & 23.0 & 9.5 \\
\hline & & After 4 weeks & 19.3 & 6.5 \\
\hline & \multirow{2}{*}{ Eyes closed } & Beginning of study & 25.4 & 9.7 \\
\hline & & After 4 weeks & 21.7 & 6.1 \\
\hline \multirow{4}{*}{ Shoes without insoles } & \multirow{2}{*}{ Eyes open } & Beginning of study & 22.4 & 8.0 \\
\hline & & After 4 weeks & 20.03 & 4.9 \\
\hline & \multirow{2}{*}{ Eyes closed } & Beginning of study & 26.4 & 8.4 \\
\hline & & After 4 weeks & 17.3 & 5.9 \\
\hline \multirow{4}{*}{ Shoes with insoles } & \multirow{2}{*}{ Eyes open } & Beginning of study & 22.7 & 9.0 \\
\hline & & After 4 weeks & 15.9 & 8.2 \\
\hline & \multirow{2}{*}{ Eyes closed } & Beginning of study & 26.2 & 7.8 \\
\hline & & After 4 weeks & 22.2 & 7.9 \\
\hline
\end{tabular}

Table 2. Repeated measure analysis of variance (displacement of center of pressure in mediolateral direction)

\begin{tabular}{cccccc}
\hline $\begin{array}{c}\text { Main Effect of Intervention (Bare feet, shoes without insoles, shoes } \\
\text { with insoles) }\end{array}$ & F & Df & P & Partial Squared \\
Main effect of visual status & 0.34 & 1.4 & 0.70 & 0.02 \\
\hline Main effect of Time (beginning of study and one month later) & 29.1 & 1 & 0.001 & 0.2 & 0.6 \\
\hline visual Status* Interaction effect of Intervention & 2.1 & 2 & 0.13 & 0.76 \\
\hline Interaction effect of time & 0.27 & 2 & 0.76 & 0.01 \\
\hline visual status* Interaction effect of time & 0.69 & 1 & 0.41 & 0.03 \\
\hline intervention* visual status* Interaction effect of time & 3.9 & 2 & 0.03 & 0.1 \\
\hline
\end{tabular}

- Significance level is considered 0.05 . 
Table 3. Mean and standard deviation for center of pressure velocity in mediolateral direction

\begin{tabular}{|c|c|c|c|c|}
\hline $\begin{array}{c}\text { Orthotic } \\
\text { intervention }\end{array}$ & Visual Status & Time & Mean $(\mathrm{mm} / \mathrm{s})$ & $\begin{array}{l}\text { Standard deviation } \\
\qquad(\mathrm{mm} / \mathrm{s})\end{array}$ \\
\hline \multirow{4}{*}{ Barefoot } & \multirow{2}{*}{ Eyes open } & Beginning of study & 6.2 & 2.2 \\
\hline & & After 4 weeks & 5.6 & 1.8 \\
\hline & \multirow{2}{*}{ Eyes closed } & Beginning of study & 8.3 & 2.7 \\
\hline & & After 4 weeks & 7.1 & 2.2 \\
\hline \multirow{4}{*}{ Shoes without insoles } & \multirow{2}{*}{ Eyes open } & Beginning of study & 6.6 & 2.2 \\
\hline & & After 4 weeks & 6.1 & 1.3 \\
\hline & \multirow{2}{*}{ Eyes closed } & Beginning of study & 9.4 & 3.2 \\
\hline & & After 4 weeks & 7.1 & 2.1 \\
\hline \multirow{4}{*}{ Shoes with insoles } & \multirow{2}{*}{ Eyes open } & Beginning of study & 6.6 & 2.1 \\
\hline & & After 4 weeks & 5.9 & 1.7 \\
\hline & \multirow{2}{*}{ Eyes closed } & Beginning of study & 9.5 & 2.1 \\
\hline & & After 4 weeks & 8.2 & 2.3 \\
\hline
\end{tabular}

Table 4. Repeated measure analysis of variance (velocity parameter for center of pressure in mediolateral direction)

\begin{tabular}{|c|c|c|c|c|}
\hline & $\mathbf{F}$ & Df & P-value & Partial Squared \\
\hline $\begin{array}{l}\text { Main Effect of Intervention (shoes without insoles, shoes with ortho- } \\
\qquad \text { sis, and without orthosis) }\end{array}$ & 2.6 & 2 & 0.086 & 0.2 \\
\hline Main effect of Visual Status & 11.3 & 1 & 0.0004 & 0.6 \\
\hline Main effect of Time & 34.8 & 1 & $0.001 \bullet$ & 0.3 \\
\hline visual status* Interaction effect of Intervention & 1.4 & 1.31 & 0.245 & 0.3 \\
\hline intervention* Interaction effect of time & 0.2 & 2 & 0.747 & 0.02 \\
\hline visual status ${ }^{*}$ Interaction effect of time & 12.3 & 1 & 0.003 & 0.4 \\
\hline intervention* visual status ${ }^{*}$ Interaction effect of time & 0.9 & 2 & 0.390 & 0.1 \\
\hline
\end{tabular}

\section{Discussion}

One of the most important criteria in fall prediction is the center of pressure displacement in mediolateral direction. Previous studies have reported a decrease or inability to control body balance in mediolateral direction, even while doing the least challenging activities or while standing, which has an increased risk of falling (Maki, Holliday, \& Topper, 1994). The aim of this study was to evaluate the effect of lateral wedged insoles on static balance of individuals diagnosed with osteoarthritis of the medial compartment of tibiofemoral joint. In this research, medical insoles with $5^{\circ}$ lateral wedges were used. The wedge degree was used based on Kerrigan's study (Kerrigan et al., 2002), which recommended the use of $5^{\circ}$ for the lateral wedge. Higher degree wedges would result in discomfort based on previous literature. The full-length lateral wedge is known to have more effects on adduction moment in comparison with heel only wedges.
Results of the current study show an insignificant difference in the average displacement and velocity of the center of pressure in mediolateral direction due to immediate use of lateral wedged insoles. In a number of previous studies (Iglesias et al., 2012), the immediate effect of using lateral wedged insoles on the average displacement and velocity of center of pressure in mediolateral direction was also insignificant, similar to the present study. However, in the study by Ganesan et al. (Ganesan et al., 2014) standing on the surface with lateral wedge compared to the flat surface decreased the average displacement and velocity of the center of pressure. In this study, no change was observed in the velocity of the center of pressure in mediolateral direction while standing on a lateral wedge. In analyzing the results, the authors consider this change in displacement of the center of pressure in mediolateral direction to be related to changes in limb alignment, especially those of the hip and an- 
kle and probable changes in muscular activity. It is noteworthy that the wedges used in Ganesan's study were 10 degrees, which is not the size used in clinical conditions. The participants of their study were also healthy young individuals, which makes the comparison of results with the current study difficult. In a follow up on the factors other than the immediate change of alignment as an effective factor in the influence of lateral wedged insoles on balance, the effects of using them after a period of four weeks was also evaluated in the current study. On the other hand, a comparison of results in two conditions of barefoot and shoes without insoles in the current study indicates that the average effect of these two conditions did not have a significant difference.

The results obtained from this study show the improvement of average displacement and velocity of the center of pressure in mediolateral direction after four weeks of using lateral wedged insoles in patients with mild and moderate osteoarthritis of the knee. A look at the previous literature shows a decrease in load on the medial knee compartment (R. S. Hinman, Bowles, \& Bennell, 2009; Hsieh \& Lee, 2014), decrease in adduction moment (R. S. Hinman, Bowles, Metcalf, Wrigley, \& Bennell, 2012) and pain reduction (Lawson et al., 2015) after using lateral wedges. Significant pain reduction after four weeks of wearing lateral wedges in shoes was observed in the present study ( $\mathrm{p}=0.001$ ). The results of studies which evaluated the relationship between balance and pain demonstrate that pain can be an independent predictor of performance and balance, and patients who felt more pain also experienced greater imbalance and performance inabilities. Improvement in balance is most often seen with pain reduction in these individuals (Menz \& Lord, 2001). Hence, pain reduction can be considered as a probable factor in improving the evaluated parameters after four weeks of using the lateral wedge in this study. Another study, the effect of custom made insoles on patients with knee osteoarthritis, immediate and also during the follow up period of 1 , 3 and 6 months, showed that the midterm use of custom made insoles ( 1 month follow up), while causing pain reduction and improvement in performance and physical activity, did not have an influence on postural stability in the mediolateral direction. The insole used in this study had a 5-degree wedge. However, in the insoles used in this study, great attention was given to preserving the subtalar neutral position and the medial longitudinal arch. In fact, the focus of this study was on the custom made insoles and on preventing excessive pronation while using lateral wedges by preserving the medial longitudinal arch. Balance evaluation was also carried out with the Biodex system.

The use of orthoses might result in an increase in somatosensory feedback necessary to control the posture, increase mechanical balance of the ankle and reduce postural sway with the passage of time (Iglesias et al., 2012). Increasing foot contact with the surface and changing the distribution of foot sole pressure can improve the somatosensory feedback necessary for long-term postural stability.

It has been shown in various research studies that the postural sway standing on both feet with closed eyes is greater than with open eyes, which is in agreement with the results of the current study (Ahmadi et al., 2014; R. Hinman, Bennell, Metcalf, \& Crossley, 2002; Hsieh \& Lee, 2014). In fact, in all the studies evaluated, the closed eye condition results in an increase in excursion of the center of pressure and velocity compared with the opened eye. In closed eye condition, the role of the vision on preserving postural control is lost. Controlling balance requires visual, vestibular, and somatosensory contributions, central integrity in the brain and dynamic responses. In the current study, the interaction effect of time and visual status on velocity of the center of pressure in mediolateral direction was significant $(\mathrm{p}=0.003$ ). Visually inspecting the data (the interaction effect graph of these parameters) showed that improving the balance after four weeks of using lateral wedged insoles is more evident in closed eye condition. Considering the greater imbalance in closed eye condition, this result is of great significance. With regards to the average displacement of the center of pressure, the interaction effect of time, visual status and intervention was also significant. It is noteworthy that these results should be interpreted more cautiously and improvement in 
the average should not be merely attributed to the parameter of time.

\section{Limitations}

This study was carried out on mild and moderate knee osteoarthritis patients and the results cannot be generalized to other grades of osteoarthritis. Drug use and dosage in the evaluated patients were not controlled. Also, hours of using the lateral wedged insoles during the four week time period was reported by the participants themselves. It is recommended to use objective tools to measure the duration of time. Insoles are used to evaluate the effect of time on using lateral wedged insoles on balance control. In this study, in order to generalize the results to more natural and non-laboratory conditions, the participants own shoes were used. Therefore, the effect of participant's shoes on the results was not eliminated. Also, the assessment of balance was only limited to one plane.

\section{Conclusion}

The results of the current study show that lateral wedges do not have an immediate effect on balance parameters of individuals diagnosed with osteoarthritis of the medial compartment of the tibiofemoral

\section{References}

Ahmadi, F., Forghany, S., Nester, C., \& Jones, R. (2014). Effects of laterally wedged insoles on static balance in patients with medial compartment knee osteoarthritis. Paper presented at the Journal of foot and ankle research. 7(Suppl 1), A22.

Alshawabka, A. Z., Liu, A., Tyson, S. F., \& Jones, R. K. (2014). The use of a lateral wedge insole to reduce knee loading when ascending and descending stairs in medial knee osteoarthritis patients. Clinical Biomechanics, 29(6), 650-656.

Brauer, S. G., Burns, Y. R., \& Galley, P. (2000). A prospective study of laboratory and clinical measures of postural stability to predict community-dwelling fallers. The Journals of Gerontology Series A: Biological Sciences and Medical Sciences, 55(8), M469-M476.

Davatchi, F., Banihashemi, A. T., Gholami, J., Faezi, joint. However, after using lateral wedged insoles for four weeks, a reduction in postural sway (displacement and velocity) of these individuals in mediolateral direction was observed, which can be indicative of improved balance.

\section{Ethical Considerations}

Participation of all individuals, after providing complete information about the goal and method of the study, was completely voluntary. Written consent was obtained from all participants. Information related to participants is kept confidential and the experiments posed no threat to the participants.

\section{Acknowledgments}

We, hereby sincerely thank all members of the Orthotics and Prosthetics department (Rehabilitation Sciences Faculty of Iran University of Medical Sciences) who provided the research team with the necessary facilities to complete the study. We would also like to thank the participants who cooperated in this research. This paper is part of a master's thesis.

\section{Conflict of Interest}

Authors declared no conflict of interest.

S. T., Forouzanfar, M. H., Salesi, M., Noorolahzadeh, E. (2009). The prevalence of musculoskeletal complaints in a rural area in Iran: a WHO-ILAR COPCORD study (stage 1, rural study) in Iran. Clinical rheumatology, 28(11), 1267-1274.

Davis, M., Ettinger, W., Neuhaus, J., \& Mallon, K. (1991). Knee osteoarthritis and physical functioning: evidence from the NHANES I Epidemiologic Followup Study. The Journal of rheumatology, 18(4), 591-598.

Ganesan, M., Lee, Y.-J., \& Aruin, A. S. (2014). The effect of lateral or medial wedges on control of postural sway in standing. Gait \& posture, 39(3), 899-903.

Gök, H., Ergin, S., \& Yavuzer, G. (2002). Kinetic and kinematic characteristics of gait in patients with medial knee arthrosis. Acta Orthopaedica Scandinavica, 73(6), 647-652.

Hassan, B., Doherty, S., Mockett, S., \& Doherty, M. 
65. The Effect of Lateral Wedge Insole ...

(2002). Effect of pain reduction on postural sway, proprioception, and quadriceps strength in subjects with knee osteoarthritis. Annals of the rheumatic diseases, 61(5), 422-428.

Hinman, R. S., Bowles, K. A., \& Bennell, K. L. (2009). Laterally wedged insoles in knee osteoarthritis: do biomechanical effects decline after one month of wear? BMC musculoskeletal disorders, 10(1), 146.

Hinman, R. S., Bowles, K. A., Metcalf, B. B., Wrigley, T. V., \& Bennell, K. L. (2012). Lateral wedge insoles for medial knee osteoarthritis: effects on lower limb frontal plane biomechanics. Clinical Biomechanics, 27(1), 2733.

Hinman, R., Bennell, K., Metcalf, B., \& Crossley, K. (2002). Balance impairments in individuals with symptomatic knee osteoarthritis: a comparison with matched controls using clinical tests. Rheumatology, 41(12), 13881394.

Hsieh, R.-L., \& Lee, W.-C. (2014). Immediate and medium-term effects of custom-moulded insoles on pain, physical function, physical activity, and balance control in patients with knee osteoarthritis. Journal of rehabilitation medicine, 46(2), 159-165.

Hsieh, R.-L., Lee, W.-C., Lo, M.-T., \& Liao, W.-C. (2013). Postural stability in patients with knee osteoarthritis: comparison with controls and evaluation of relationships between postural stability scores and international classification of functioning, disability and health components. Archives of physical medicine and rehabilitation, 94(2), 340-346. e341.

Iglesias, M. E. L., de Bengoa Vallejo, R. B., \& Pena, D. P. (2012). Impact of soft and hard insole density on postural stability in older adults. Geriatric Nursing, 33(4), 264-271.

Kahlaee, A. H., Sadeghi, H., Jamebozorgi, A., \& Yousefian Molla, R. (2015). The effect of early progressive isotonic exercise therapy on balance control of patients with total knee replacement. Physical Therapy 5(1), 55-59.

Katsuragawa, Y., Fukui, N., \& Nakamura, K. (1999). Change of bone mineral density with valgus knee bracing. International orthopaedics, 23(3), 164-167.
Kerrigan, D. C., Lelas, J. L., Goggins, J., Merriman, G. J., Kaplan, R. J., \& Felson, D. T. (2002). Effectiveness of a lateral-wedge insole on knee varus torque in patients with knee osteoarthritis. Archives of physical medicine and rehabilitation, 83(7), 889-893.

Lawson, T., Morrison, A., Blaxland, S., Wenman, M., Schmidt, C. G., \& Hunt, M. A. (2015). Laboratory-based measurement of standing balance in individuals with knee osteoarthritis: A systematic review. Clinical Biomechanics, 30(4), 330-342.

Maki, B. E., Holliday, P. J., \& Topper, A. K. (1994). A prospective study of postural balance and risk of falling in an ambulatory and independent elderly population. Journal of gerontology, 49(2), M72-M84.

Maly, M. R., Culham, E. G., \& Costigan, P. A. (2002). Static and dynamic biomechanics of foot orthoses in people with medial compartment knee osteoarthritis. Clinical Biomechanics, 17(8), 603-610.

Menz, H. B., \& Lord, S. R. (2001). Foot pain impairs balance and functional ability in community-dwelling older people. Journal of the American Podiatric Medical Association, 91(5), 222-229.

Mousavi, S. M. E. (2001). The Identification of Influential Factors in Knee Osteoarthritis and Its Prevalence among Referals to Orthopedic Clinics in Tehran. Archives of Rehabilitation, 2(1), 14-20.

Parkes, M. J., Maricar, N., Lunt, M., LaValley, M. P., Jones, R. K., Segal, N. A., Felson, D. T. (2013). Lateral wedge insoles as a conservative treatment for pain in patients with medial knee osteoarthritis: a meta-analysis. Jama, 310(7), 722-730.

Pritzker, K., Gay, S., Jimenez, S., Ostergaard, K., Pelletier, J.-P., Revell, P., Van den Berg, W. (2006). Osteoarthritis cartilage histopathology: grading and staging. Osteoarthritis and cartilage, 14(1), 13-29.

Russell, E. M., \& Hamill, J. (2011). Lateral wedges decrease biomechanical risk factors for knee osteoarthritis in obese women. Journal of Biomechanics, 44(12), 22862291.

Sadeghi, H., \& Alirezaei, F. (2008). The Effect of Water Exercise Program on Static and Dynamic Balance in El- 
derly Women. Iranian Journal of Ageing, 2(4), 402-409.

Satvati, B., Karimi, M., Tahmasebi Boldaji, R., \& Pool, F. (2013). Standing stability evaluation in subjects with flat foot. J Res Rehabil Sci, 8(8): 1277-84.

Sohrabi, M., Khademi-Kalantari, K., AkbarZadehBaghban, A.-R., Rezaee, M., \& Hosseini, S. M. (2014). Comparison of the effects of shoe orthotics on the replacement of center of pressure in patients with severe medial compartment knee osteoarthritis. Rehabilitation Medicine, 2(2).
Toda, Y., \& Segal, N. (2002). Usefulness of an insole with subtalar strapping for analgesia in patients with medial compartment osteoarthritis of the knee. Arthritis Care \& Research, 47(5), 468-473. 


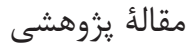 \\ تأثير كفى با كَؤ خارجى بر تعادل ايستايى داخلى -خارجى در افراد مبتلا به استئو آرتريت بخش داخلى زانو}

مهسا زنتىى'، مريم جلالى "*، الهام اسفنديارى'، حميدرضا يزدى'

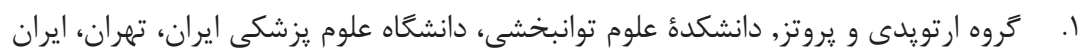

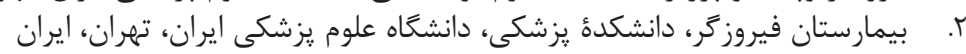

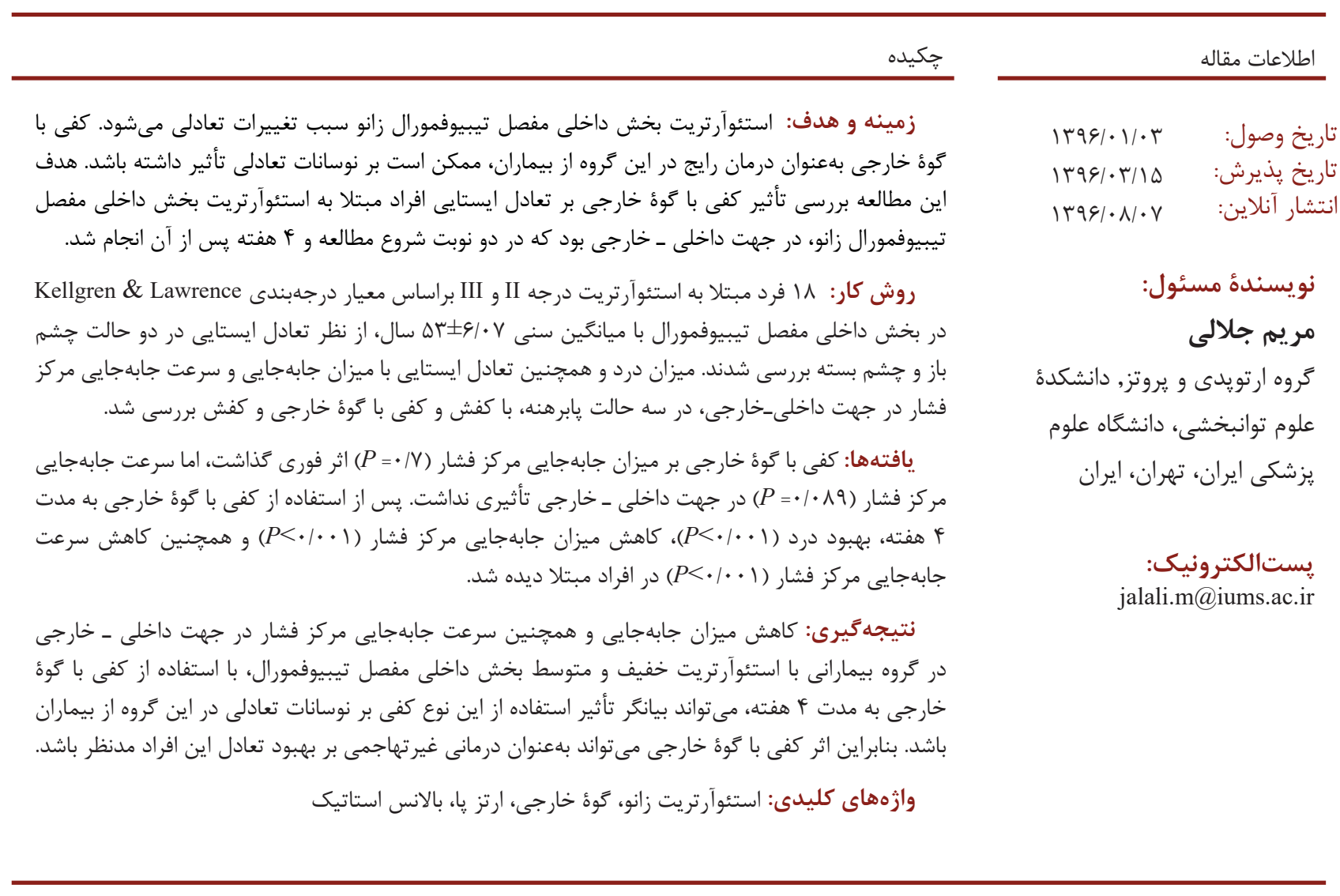

